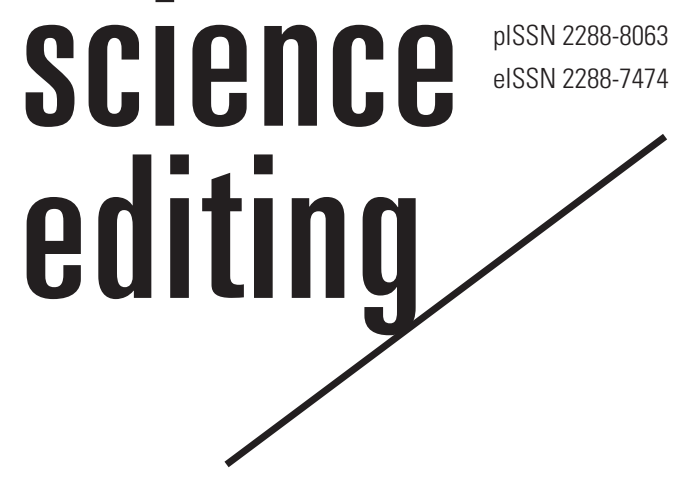

\title{
Korean medical students' knowledge about and attitudes towards plagiarism according to their commission of plagiarism
}

\author{
Man Sup Lim', Sun Huh² \\ 'Department of Medical Education, ${ }^{2}$ Department of Parasitology and Institute of Medical Education, College of Medicine, \\ Hallym University, Chuncheon, Korea
}

\begin{abstract}
Purpose: This study investigated Korean medical students' knowledge about and attitudes towards plagiarism according to their commission of plagiarism. Furthermore, the institutional environment regarding plagiarism was assessed.

Methods: A questionnaire provided by Turnitin was distributed to 67 first-year medical students of Hallym University, Korea in December 17, 2015 through SurveyMonkey, a web survey platform. Of the 67 subjects, responses from 60 students $(89.6 \%)$ were analyzed with descriptive statistics and a comparative analysis.

Results: The respondents' average knowledge level about plagiarism, measured as the item difficulty index for the relevant 8 items, was 0.658 (maximum 1). More than half did not know where they could find guidance about how to reference others' work. They were only a little confident (41.7\%) or not confident (11.7\%) in referencing others' work. They felt that plagiarism was not dealt with seriously at the university (53.3\%). Eighty percent of students wanted their instructors to use text-matching software to check students' work, and many of them thought that text-matching software helps them to spend more time making sure that references are correct (48.3\%). Forty-six (75.4\%) students reported having copied and pasted from the internet for their work without citing the original work. There were no significant differences in knowledge about plagiarism, attitudes towards classmates who plagiarize, or recommended actions against classmates who plagiarize according to whether students had committed plagiarism.
\end{abstract}

Received: July 21, 2019

Accepted: July 23, 2019

Correspondence to Sun Huh

shuh@hallym.ac.kr

Conclusion: The medical students' knowledge about plagiarism was insufficient. This medical school should introduce more intensive training on how to correctly reference others' work and on the concept of plagiarism. 


\section{Introduction}

Plagiarism can be defined as "the appropriation of another person's ideas, processes, results, or words without giving appropriate credit" according to the Office of Research Integrity in the United States Department of Health and Human Services [1]. The same definition is provided in Korea in the Ministry of Education's guideline on research ethics [2]. However, it is difficult to define to what extent anyone's opinion or writing reflects his or her own ideas. Frequently, thought and writing present an individual's interpretation and summary of external sources, such as books, journals, mass media, and ideas verbally expressed by others, including family members and acquaintances. It is impossible for everybody to think or write without drawing upon outside information. Although it is difficult to produce original ideas, it is possible for a person to articulate his or her own thoughts or knowledge in written form without copying others' work. To do so, it is important to write one's own thoughts after interpreting previous work. Paraphrasing using one's own logic is also required. If it is necessary to cite another person's work in its original wording, the quoted text should be clearly indicated (e.g., using quotation marks), and the original work should be appropriately cited.

The major types of research misconduct include fabrication, falsification, and plagiarism. Therefore, it is necessary to avoid plagiarism in scientific writing. For this reason, appropriate writing is taught at the university level. Korean medical students are expected to write an article during their training period in hospitals as residents, because it is mandatory for them to publish or submit articles to medical journals to be eligible to take specialty-specific board examinations. Some medical students will become researchers or professors at university hospitals or research institutes in the future, in which case, they would write articles as part of their routine work.

This study investigated Korean medical students' knowledge about and attitudes towards plagiarism according to their commission of plagiarism. Furthermore, the institutional environment regarding plagiarism was examined. The results will provide support for the university's policy on scientific writing classes and will help promote the prevention of plagiarism by graduates of medical schools in Korea.

The null hypotheses of this study were as follows: first, medical students' knowledge about plagiarism would not differ depending on whether they had committed plagiarism; second, medical students' attitudes towards plagiarism would not differ according to whether they had committed plagiarism; and third, medical students' recommended actions against plagiarism would not differ according to whether they had committed plagiarism.

\section{Methods}

Ethics statement: Informed consent was obtained from subjects as part of the first page of the survey. They were able to quit the web survey at any time during the survey process without any restrictions.

Study design: This was an observational study using a known survey tool.

Setting/participants: Sixty-seven first-year medical students in Hallym University in 2015 were invited to complete the survey. The survey was conducted in December 17, 2015. The survey tool was a questionnaire used for surveys on plagiarism by Turnitin. It was dispatched to the students through SurveyMonkey, a web survey platform. The content of the survey is presented in Suppl. 1. Of the 67 students, 60 (89.6\%) responded to the survey.

Validity and reliability of the survey tool: This tool had already been developed and used by Turnitin; therefore, no further validity testing was done. The survey tool consisted of 26 items, which are listed in Suppl. 1. The first three items gathered demographic information on the subjects. Eight items measured knowledge about plagiarism. Five items assessed the university environment regarding plagiarism. The number of items on attitudes towards plagiarism was five. Four items assessed subjects' commission of plagiarism. The final item solicited further opinions on plagiarism. The reliability test showed that the Cronbach a value was 0.8487 for 17 survey items. Some items were excluded from the reliability test because they did not have nominal or binomial scale options, had responses from only some subjects, or gathered information on subjects' past commission of plagiarism. The items included in the reliability test are listed in Suppl. 2.

Variables: The variables measured were knowledge about plagiarism, attitudes towards plagiarism, recommended actions against plagiarism, and commission of plagiarism.

Data sources/measurement: The sources were response data from 60 medical students collected from the survey. The measurement methods were descriptive statistics and a comparative analysis of knowledge about and attitudes towards plagiarism between students who had committed plagiarism and those who had not committed plagiarism.

Bias: There was no noteworthy source of bias during data collection and analysis.

Study size: If the t-test was done to compare mean values between 2 independent groups, an adequate sample size was estimated as 66 with the following input parameters: effect size (D), 0.7 ; $\alpha$ error probability, 0.05 ; power ( $1-\beta$ probability), 0.75 ; and allocation ratio (N2/N1), 2 [3].

Quantitative variables: There were no quantitative variables. All variables were qualitative. 
Statistical methods: The results were analyzed with DBSTAT ver. 5.0 (DBSTTAT Co., Chuncheon, Korea) for descriptive and comparative analyses.

\section{Results}

All response data are available in Dataset 1.

Average knowledge about plagiarism: The results for these 8 items are presented in Fig. 1. The item difficulty index for knowledge about plagiarism was 0.658 . Replies of "not sure" were counted as a wrong answer, equivalent to "no."

Environment regarding plagiarism: More than half of the respondents did not know where they could find guidance about how to reference others' work (Fig. 2). Thirty-two stu- dents (54.2\%) said that university guidelines explained how to cite others' work; while 27 students said that they did not (45.8\%). More than half of the students (53.3\%) felt that plagiarism was not dealt with seriously at the university. Twentyfive students (41.7\%) said that teachers check whether students appropriately cite others' work. Sixteen students (26.7\%) said that teachers always spot unoriginal materials.

Attitudes towards plagiarism: Students were only a little confident (41.7\%) or not confident (11.7\%) in referencing others' work (Fig. 3). Forty-eight students (80.0\%) wanted their teachers to use text-matching software to check students' work. Twenty-nine students thought that text-matching software helps them to spend more time making sure that references are correct (48.3\%). Many students felt that by copying

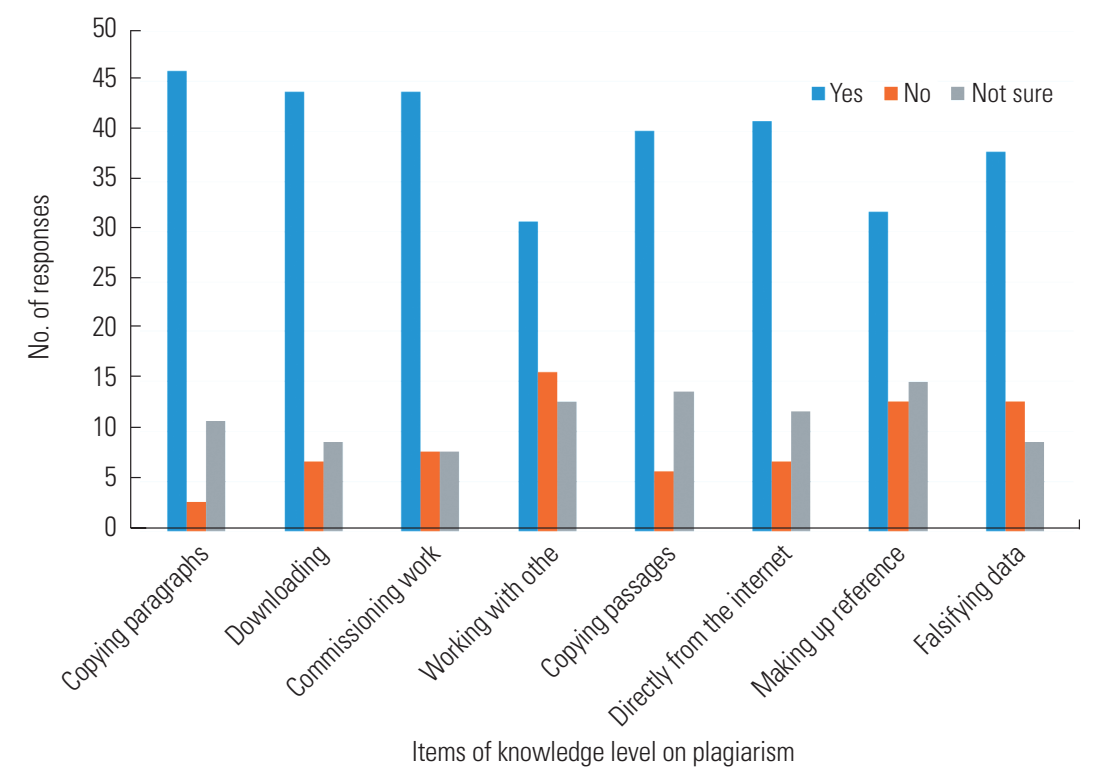

Fig. 1. Knowledge about plagiarism among 60 medical students at Hallym University, Korea, who responded on December 17, 2015.

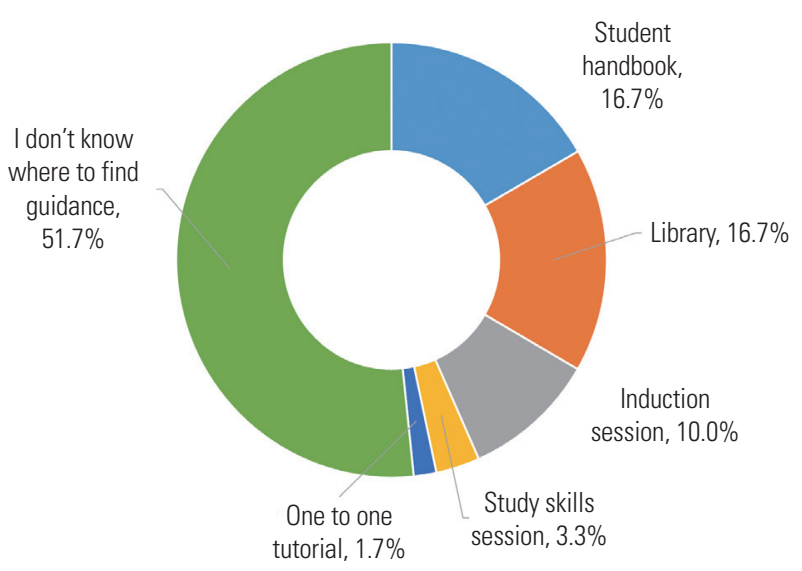

Fig. 2. Where 60 medical students at Hallym University found guidance for citing others' work.

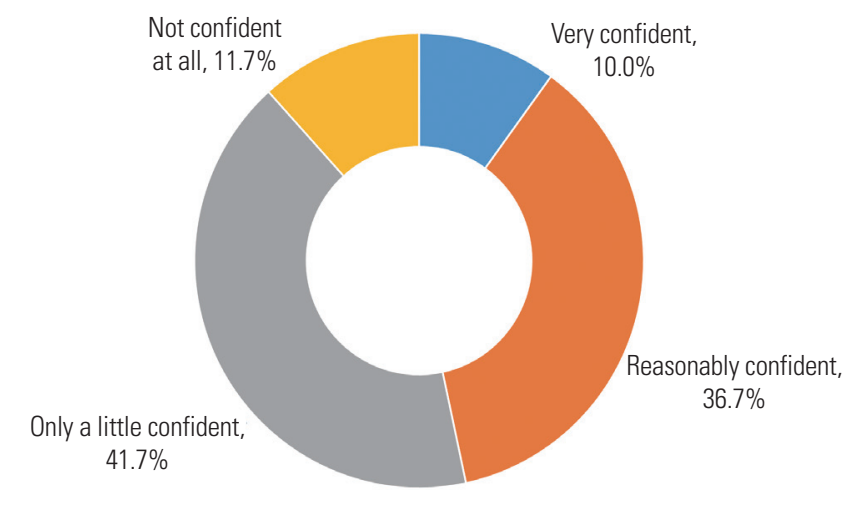

Fig. 3. Medical students' confidence in citing others' work. 
and pasting materials from the internet or using a writing service, their classmates would devalue their qualification (48.3\%) (Fig. 4). Medical students' recommended actions against classmates who plagiarize others' work are presented in Fig. 5, with options including a formal warning, a mark of zero for the assignment, having to resit the assignment, having to resit the module, and being expelled from the course.

Commission of plagiarism: Forty-six (76.7\%) students reported having copied and pasted from the internet for their work without citing the original work. The responses on the degree of plagiarism were as follows: a few words, 4; a few sentences, 27; and a paragraph or more, 17. No responses were present for the item, "all of my assignment was copied from the internet." Two students who reported not having committed plagiarism responded to the item on the degree of plagiarism. Since this pattern of responses is logically inconsistent, their responses were not considered when tabulating students' com-

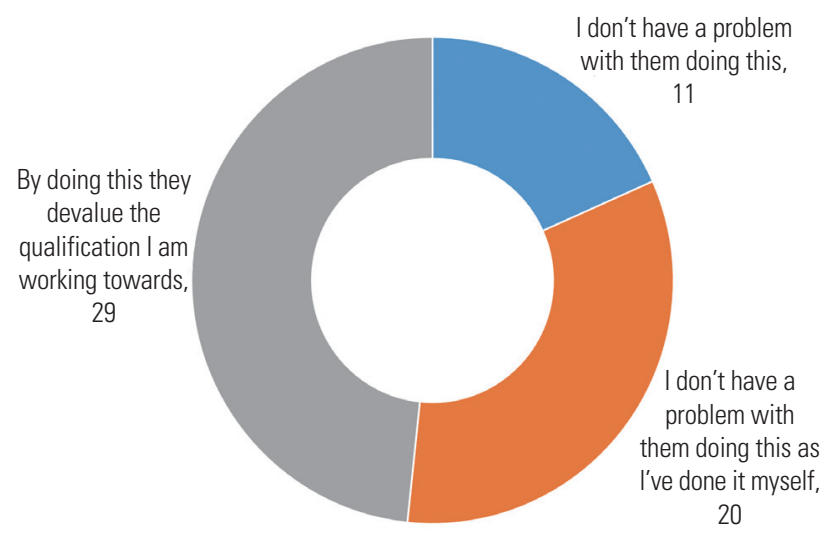

Fig. 4. Attitudes of 60 medical students about students who copy and paste material from the internet or who use essay-writing services and then submit this work as their own.

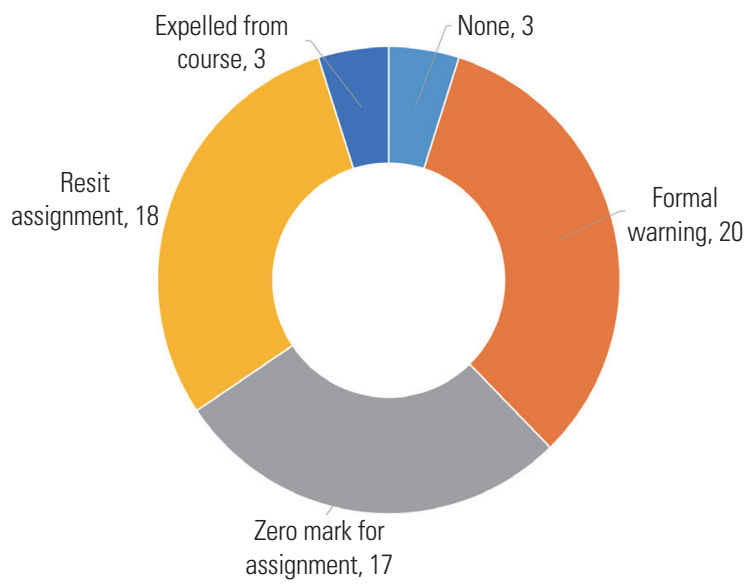

Fig. 5. Medical students' recommended actions against classmates who plagiarize others' work. mission of plagiarism. Twelve students (20.3\%) reported having used essay-writing services to submit their homework. Fifty-four students (90.0\%) knew classmates who had copied and pasted materials from the internet or used a writing service.

Comparison of knowledge about plagiarism according to commission of plagiarism: There was no significant difference in knowledge about plagiarism according to whether students had committed plagiarism, as determined through 2-way repeatedmeasures analysis of variance (significance level $\alpha=0.05, \mathrm{~F}=$ 4.01, $\mathrm{P}=0.9775$ ) (Fig. 6).

Comparison of attitudes towards classmates who plagiarized others' work: There was no significant difference in attitudes between students who had plagiarized and those who had not (chi-square test, $\mathrm{P}=0.8786$ ) (Fig. 7). The Student t-test could not be used because the sample did not show a normal distribution. Two options ("I don't have a problem with them doing this" and "I don't have a problem with them doing this as I've done it myself!") were treated as no. The option "By doing this they devalue the qualification I am working towards" was treated as yes.

Comparison of recommended actions against classmates who

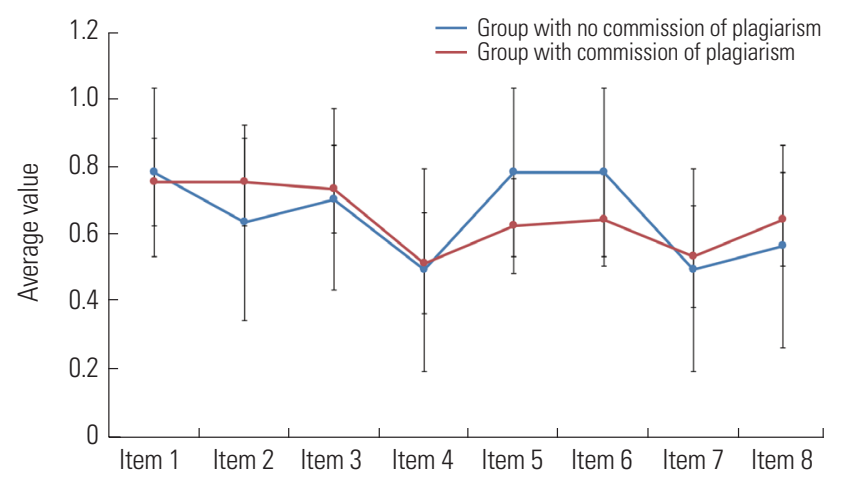

Fig. 6. Comparison of knowledge about plagiarism on the relevant 8 items according to commission of plagiarism. Bar=standard deviation.

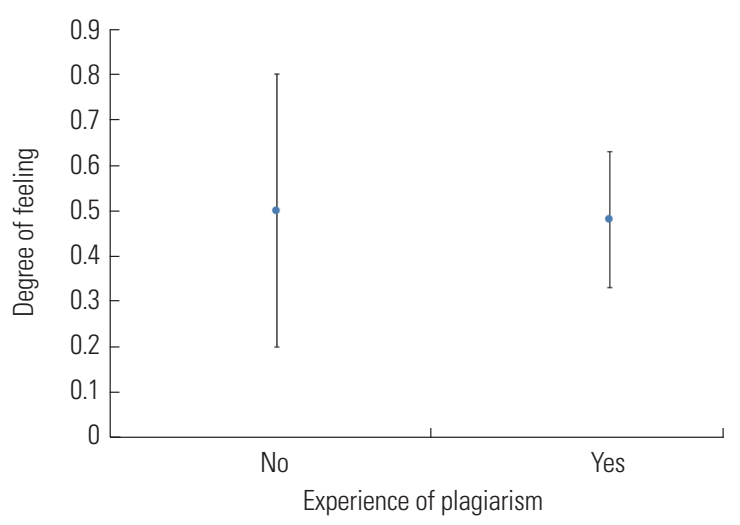

Fig. 7. Medical students' attitudes towards classmates who plagiarize others' work. 


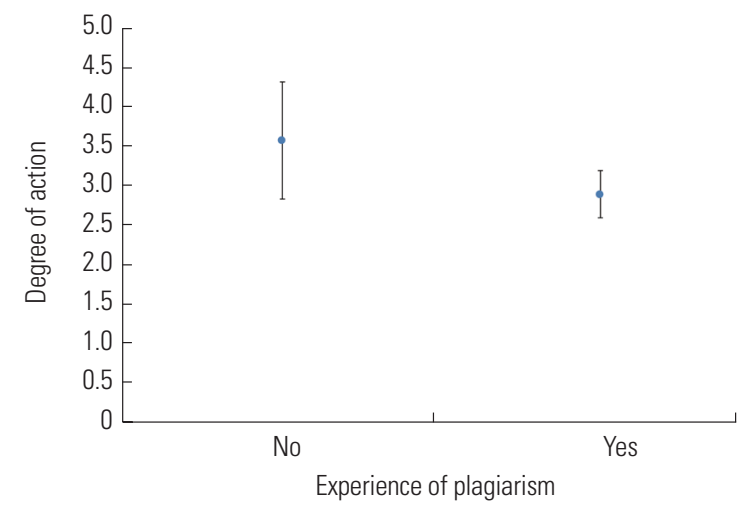

Fig. 8. Degree of medical students' recommended actions against classmates who plagiarize others' work.

plagiarize others' work: The options for actions that should be taken against students who plagiarize were transformed to a nominal scale in order of increasing severity, as follows: none, 1; formal warning, 2; a mark of zero for the assignment, 3; having to resit the assignment, 4 ; having to resit the module, 5 ; being expelled from the course, 6; and a fine, 7 (Fig. 8). The Mann-Whitney U-test was used because the samples did show a normal distribution. No significant difference was found in the strength of recommended actions between students depending on whether they had committed plagiarism $(\mathrm{P}=0.0823)$.

\section{Discussion}

Key results: The knowledge of medical students about plagiarism was insufficient. The mean item difficulty index (score) of the 8 relevant items was 0.658 . There was no significant difference in knowledge level according to plagiarism commission. Medical students' environment regarding plagiarism was also inadequate. Forty-six (76.7\%) students had committed plagiarism. There was no significant difference in attitudes towards classmates who plagiarize others' work based on commission of plagiarism. Likewise, no significant difference was found in the strength of recommended against classmates who plagiarize according to whether students had committed plagiarism.

Interpretation and suggestions: The first null hypothesis ("medical students' knowledge about plagiarism would not differ depending on whether they had committed plagiarism") was accepted. The second null hypothesis ('medical students' attitudes about plagiarism would not differ according to whether they had committed plagiarism") was also accepted. Finally, the third null hypothesis ("medical students' recommended actions against plagiarism would not differ according to whether they had committed plagiarism") was accepted.
The lack of differences in some variables according to students' commission of plagiarism may have originated from the fact that their level of knowledge about plagiarism was not adequate. If someone does not know what the best practice is, it is difficult to urge him or her to carry out that best practice. Additionally, a merit of this study is that it utilized the survey questionnaire on plagiarism provided by Turnitin. Therefore, it was possible to analyze the general situation regarding plagiarism at a medical school in Korea.

What can be suggested based on the above results? Hallym University has introduced the use of plagiarism detection programs such as Turnitin or CopyKiller (https://www.copykiller.com/), the latter of which is a Korea-based plagiarism detection program, to help students and teachers to prevent plagiarism. Therefore, those programs should be introduced to students more emphatically. If students understand the merits of those programs, they will be able to prevent plagiarism more efficiently. The institutional environment also should be improved so that students understand and practice good writing. Teachers should use plagiarism-detecting programs more actively to help students' writing. More thorough training should be given on appropriate citation of others' work and performing one's own interpretation of data.

Comparison with previous relevant studies: In literature databases including PubMed, KoreaMed, Web of Science Core Collection, Scopus, and Google Scholar, when using the search term (plagiarism AND "medical students"), studies on plagiarism among medical students in Korea are rare. Only 1 report on plagiarism during a problem-based learning course in medical school in Korea was published. During that course, $62 \%$ of students copied and pasted from websites; furthermore, they were not aware that plagiarism is a serious problem [4]. Recent reports on medical students' plagiarism outside of Korea can be summarized as follows. In a medical school in Malaysia, 257 of 464 students (55.4\%) responded that they copied assignment from other students [5]; in 2 medical colleges in Pakistan, of 1,100 participants, 783 students $(71.18 \%)$ said that they used others' work without citation [6]; and in Iraq, out of 280 medical students, 165 (58.9\%) practiced plagiarism [7]. The above data on plagiarism are comparable to the results of this study, in which 46 of $60 \mathrm{stu}-$ dents (76.7\%) reported having committed plagiarism.

Limitations: This was a single institution-based study with a relatively small number of subjects, making it difficult to generalize the results and interpretation to other medical students outside of Hallym University. Due to the lack of a normal distribution, it was not possible to conduct a parametric analysis, except for knowledge level according to plagiarism commission. Generalizability: As mentioned as a limitation of this study, one should be cautious about generalizing these results to other 
medical schools in Korea and abroad. To obtain a more comprehensive assessment of the status of plagiarism among Korean medical students, multi-center studies are recommended with the same survey tool. It is also recommended that medical schools outside of Korea should adopt this tool. Another merit of this study is that it furnishes further confirmation of the reliability of the survey questionnaire on plagiarism provided by Turnitin. Therefore, this survey tool may be able to be used in other settings with more confidence. This tool can be introduced in all universities throughout the world, regardless of whether it is applied to undergraduates or graduates.

Conclusion: In this study, medical students' knowledge about plagiarism, environment regarding plagiarism, commission of plagiarism, attitudes towards plagiarism, and recommended actions against plagiarism were evaluated. No significant differences were found in knowledge, attitudes, and recommended actions against plagiarism between students who had committed plagiarism and those who had not. Although these results are from a single institution, Korean medical schools should present a clearer introduction describing how to correctly reference others' work and the concept of plagiarism. Students should be able to use plagiarism detection programs provided by the University Library, such as Turnitin or CopyKiller, without difficulty to prevent plagiarism in their writing.

\section{Conflict of Interest}

The survey tool was obtained from Turnitin with generous permission; however, there was no financial support from Turnitin. Staff members of Turnitin were not involved in any processes of the survey, the analysis of data, or the interpretation. Turnitin and Copy Killer were mentioned not for propagation of the commercial products, but for educational purposes. Otherwise, no potential conflict of interest relevant to this article was reported.

\section{Data Availability}

Dataset is available from the Harvard Dataverse at: https://doi. org/10.7910/DVN/419NYZ.

Dataset 1. Response data of medical students at Hallym University to the survey questionnaire on plagiarism provided by Turnitin.

\section{Supplementary Material}

Supplementary files are available from Harvard Dataverse at: https://doi.org/10.7910/DVN/419NYZ.

Suppl. 1. Survey questionnaire on plagiarism provided by Turnitin.

Suppl. 2. Results of the reliability test and items included from the survey questionnaire on plagiarism provided by Turnitin.

\section{References}

1. Office of Research Integrity in United States Department of Health and Human Services. Definition of research misconduct [Internet]. Rockville: Office of Research Integrity in United States Department of Health and Human Services [cited 2019 Jul 21]. Available from: https://ori.hhs.gov/ definition-misconduct

2. National Law Information Center. Ministry of Education's guideline to secure research ethics [Internet]. Seoul: $\mathrm{Na}$ tional Law Information Center [cited 2019 Jul 21]. Available from: http://www.law.go.kr/행정규칙/연구윤리확보 를위한지침

3. Faul F, Erdfelder E, Buchner A, Lang AG. Statistical power analyses using $G^{\star}$ Power 3.1: tests for correlation and regression analyses. Behav Res Methods 2009;41:1149-60. https://doi.org/10.3758/BRM.41.4.1149

4. Kim KJ, Hwang JY, Lee DW, Shim MS. Medical student plagiarism in problem-based learning courses. Med Educ Online 2016;21:30537. https://doi.org/10.3402/meo.v21.30537

5. Yadav H, Jegasothy R, Ramakrishnappa S, Mohanraj J, Senan P. Unethical behavior and professionalism among medical students in a private medical university in Malaysia. BMC Med Educ 2019;19:218. https://doi.org/10.1186/ s12909-019-1662-3

6. Javaeed A, Khan AS, Khan SH, Ghauri SK. Perceptions of plagiarism among undergraduate medical students in Rawalpindi, Pakistan. Pak J Med Sci 2019;35:532-6. https://doi. org/10.12669/pjms.35.2.33

7. Ismail KH. Perceptions of plagiarism among medical and nursing students in Erbil, Iraq. Sultan Qaboos Univ Med J 2018;18:e196-201. https://doi.org/10.18295/squmj.2018. 18.02 .012 